\title{
EDITORIAL
}

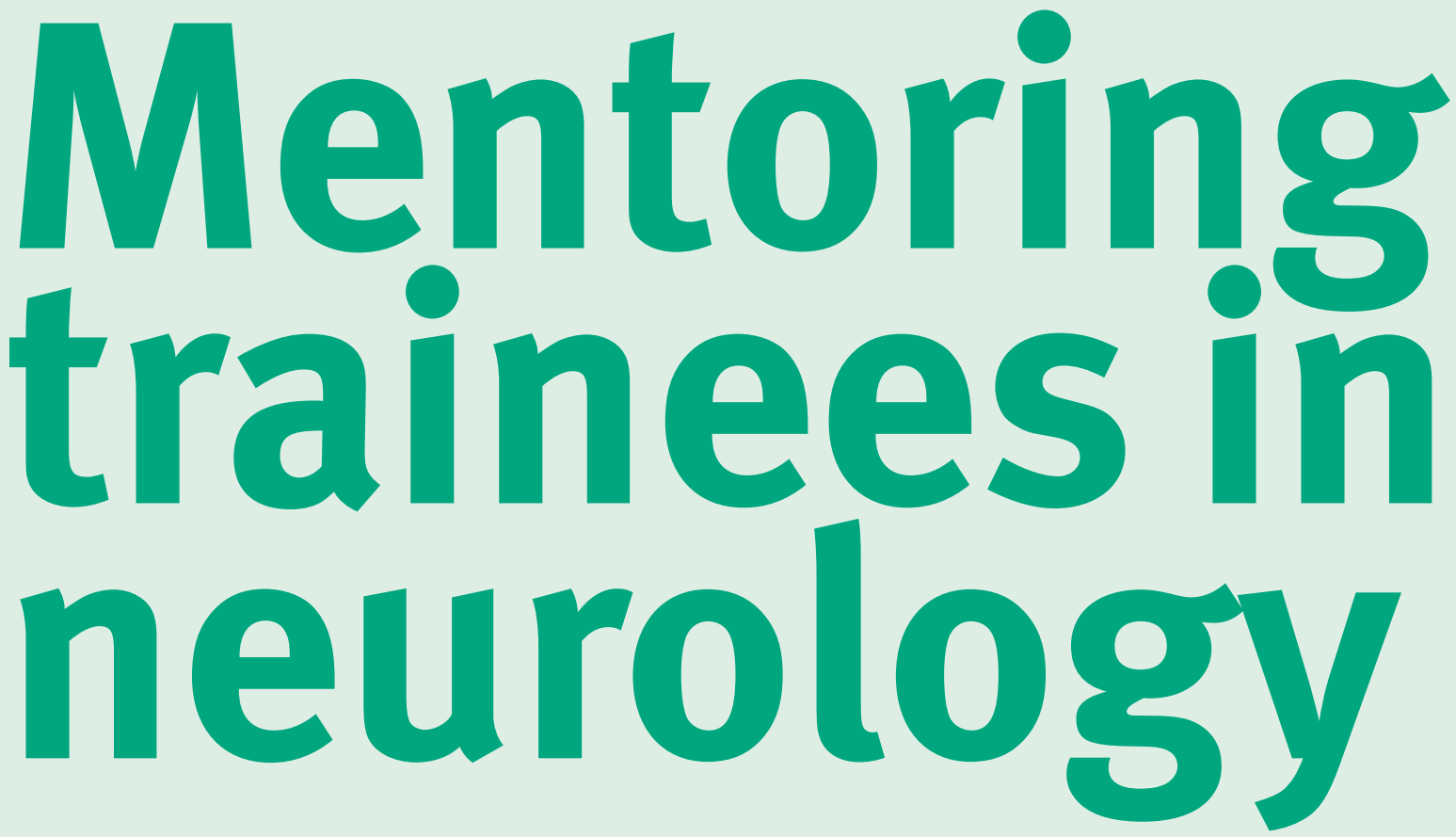

\section{M. Wiles}

Professor of Neurology, Department of Neurology, School of Medicine, Cardiff University;

E-mail:wiles@cf.ac.uk

Practical Neurology, 2005, 5, 130-131

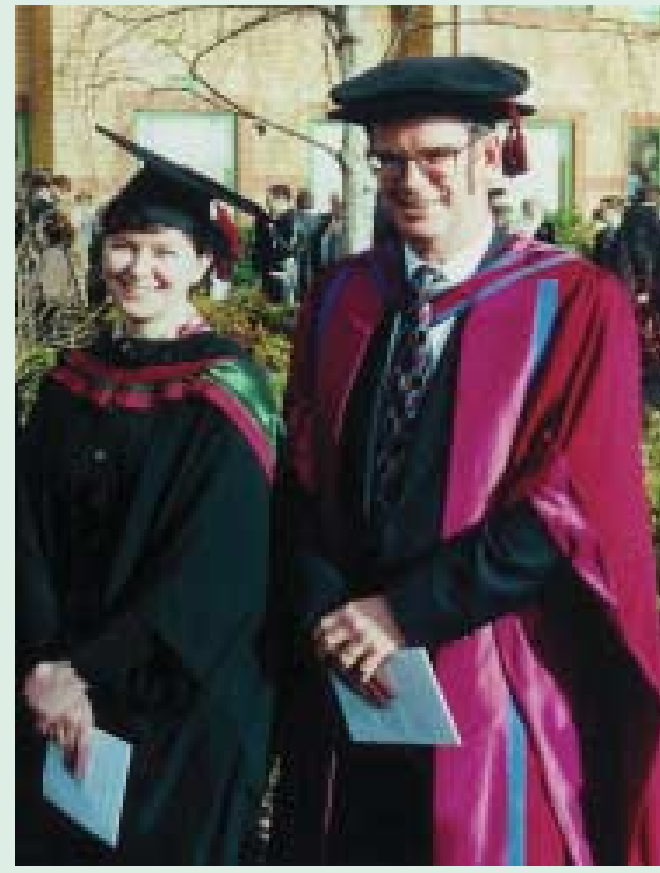

Mentor and mentee at graduation
A mentor is variously defined as a wise, experienced and trusted counsellor, or a more senior and experienced colleague who helps advise a junior employee (emphasizing a prominent role in the commercial world). Also the words 'tutor' and 'trainer' are used. There is an anecdotal literatureabout medical figures of the past (including neurologists), who their influences (mentors) were, and who in turn they influenced. Indeed, many will recall senior figures from their own neurology training who madea personal impact for good or for ill, with whom they associate achievement and learning, or a desire to emulate. But these heroes who so influenced practice or career prospects may have been unaware of it, or have done so unasked! If such peoplewere really mentors, it was in a very informal sense.

The present public climate for medical practitioners has provoked a moreformal approach 
to mentoring which may easily (but erroneously) be perceived as having a remedial quality: an association with the failing or returning (following sickness or suspension) doctor who thus requires some 'mentoring' to get him or her back on track - an arm of clinical governance, one step short of the regulator. This unsympathetic view possibly reflects a profession conditioned by training and personality to be robustly independent, to require little or no support from others, and to regard the seeking of help as essentially feeble or 'I managed, why can't you? H owever, recent reports attest to the benefits of mentoring for trainees and specialists alike (Oxley \& Flemming et al. 2004). For example, the UK Academy of Medical Royal Colleges clearly sees a mentorship role for some more senior doctors in assisting others to reach their full professional potential (Black \& Craft 2004), and this process is also emphasized from the perspective of training in academic medicine (Academic Careers 2004). Mentoring is especially emphasized when doctors change role, e.g. newly appointed specialists (consultants), those taking on managerial roles, those changing country, or returning from ill-health - rather than from a traineeperspective (Cohen $\&$ Rooney etal. 2004). But the trainee can obviously be helped by knowledgeable guidance, sensible advice and timely discussion with a more experienced professional in the sameor a related discipline.

M ost trainees - at least in the UK - have a so-called educational supervisor, responsible for regular appraisal of their progress through training. In neurology the supervisor is usually a specialist neurologist. To what extent this relationship can deal with broader professional and personal matters embraced by the term mentor isvery uncertain becauseof issues of personality, time available, and inclination as well as the potential problem of a professionally dependent relationship. This issue of professional or institutional dependency getting in the way of an effective mentor-mentee relationship perhaps goes to the heart of its nature. Some mentees benefit from a seniorjunior relationship where the 'flow of benefit' is from the experienced to the inexperienced. But mentorship can also be more of a shared dialogue based on trust between equals (so called co-mentoring) (Oxley et al. 2004). The mentor needs someshared experiencewith the mentee but does not necessarily need to be in thesamedepartmentor institution (other than for convenience of meeting) - some distance may help.

The details of how best to run a mentoring scheme, its level of formality, method of access and training requirements are uncertain (Oxley etal. 2004). M entees should be able to choose their mentor, and face-to-face knowledge of the person isimportant (relying on e mail al onehas limitations). Time, patience and consistency in a mentor are important qualities. Mentorship should not be to do with bucking the system and the trainee moving ahead through special favours, although who can deny that good timely advice from the 'inside' may advance careers? M entorship haseverything to do with constructive 'active' listening, exploring issues and difficulties from a developmental perspective, and hel ping trainees to work out their own salvation - or at least setting up a few signposts. Not everyone is a natural mentor although, as medical practitioners, we should have an affinity for the listening process. And some discussion, experience or training seem likely to help.

In common with all such burgeoning schemes, the increased formality of trainee mentoring means increase in cost, time and resources. A relatively informal but publicised system based on empathic people making themselves accessible to broader professional, academic and personal issues raised by trainees through regular, non-threatening, one- toone discussion seems like common sense, but probably a formal administrative structure is inevitable (if only to makesure all thetrainees do get a mentor). Fortunately, many educational supervisorscan comfortably fulfil a dual role and become mentors with fairly minimal extra effort if they and the trainee both agree to this.

\section{REFERENCES}

Academic Careers Sub-Committee of Modernising Medical Careers and the UK Clinical Research Collaboration (2004) Medically- and dentally-qualified academic staff - recommendations for training the researchersand educators of the future (draft for consultation). http://www.mmc.nhs.uk/academic medicine.asp [last accessed $31 \mathrm{M}$ arch 2005].

Black C \& CraftA (2004) Thecompetent doctor: a paper for discussion. Clinical Medicine 4, 527-33.

Cohen C, Rooney G, Maw R etal. (2004) Mentoring. Clinical Medicine, 4, 584-6.

Oxley J, Flemming B, Golding L, Pask $\mathrm{H} \&$ Steven A (2004) M entoring for doctors: enhancing the benefit. A working paper produced on behalf of the Doctor's Forum. http://freespace.virgin.net/ncssd.org/ M entor1.pdf [last accessed $31 \mathrm{M}$ arch 2005]. 